\title{
O CORPO COMO PRINCÍPIO ${ }^{1}$
}

\author{
Mário Fernando BOLOGNESI ${ }^{2}$
}

- RESUMO: A matéria-prima do espetáculo de circo é o corpo do artista, ora sublime, ora grotesco. O corpo sublime, no chão ou nas alturas, desafia, em forma de espetáculo, as leis naturais. No momento seguinte, o espetáculo é "interrompido" e o público é acometido pela descontração e pelo grotesco dos palhaços. O espetáculo circense, assim, se desloca, com facilidade e maestria, entre o riso e a morte.

- PALAVRAS-CHAVE: Circo; palhaço; riso.

Pode-se supor que em algum momento da vida, na infância ou anteontem, todos nós tenhamos adentrado em um circo para assistir a um espetáculo. Pode-se igualmente supor que tal experiência tenha provocado um certo fascínio, ainda hoje presente na memória. O espetáculo deslumbrante do circo é de tal forma fecundo que normalmente é tomado, no imaginário, como uma experiência de liberdade. A arena circular iluminada catalisa a fascinação e se transforma em um espaço de realização do impossível. O limite dessa arena é dado pelas cadeiras e arquibancadas. Mas o limite territorial não constrange o encantamento.

O picadeiro do circo, entretanto, não pode ser associado ao círculo tal como adotado pelos gregos da época heróica. No âmbito da nobreza

\footnotetext{
1 Resultado parcial da pesquisa Clowns: dramaturgia, interpretação e encenação, que conta com auxílio à pesquisa da Fapesp.

2 Departamento de Filosofia da Faculdade de Filosofia e Ciências - UNESP - 17525-900 - Marília SP. Pesquisador CNPq.
} 
guerreira dos Aqueus e seus descendentes, a adoção da forma circular encontrava seu complemento no diálogo, nas assembléias militares. A eqüidistância em relação ao centro tinha sua correspondência no uso da palavra. O lugar central do círculo não era ocupado por ninguém, e o foco de atenção se deslocava para as bordas. Assim, todos os nobres guerreiros se mantinham em condições de igualdade na assembléia, tanto na disposição espacial quanto na forma dialogada da palavra. O circo e seu picadeiro concentram uma outra relação: o público não encontra naquele espaço a eqüidistância institucional a partir da qual os guerreiros dividiam os bens pilhados. A forma circular é outra (Duarte, 1995, p.180). Agora, ela corresponde à divisão entre o passivo e o ativo, entre artistas e platéia, ou, se preferirem, entre produtores e consumidores.

O circo, tal como foi organizado no fim do século XVIII e que veio a se firmar no XIX, é resultado da conjunção de dois universos espetaculares até então distintos: de um lado, a arte eqüestre inglesa que era desenvolvida nos quartéis; de outro, as proezas dos saltimbancos. Esses universos, contudo, estavam em "vias de extinção", dadas as circunstâncias da nova sociedade mercantil emergente, coroada politicamente com a Revolução Francesa (Burke, 1993, p.270 ss.). Nesse quadro, a anterior e aristocrática ordem militar transferiu seu domínio sobre o cavalo para o ambiente comercial, após Phillip Astley, um suboficial da cavalaria inglesa, descobrir que graças à força centrífuga um homem pode manter-se em pé no dorso de um cavalo, em uma arena de treze metros. Tão logo se firmou, tal modalidade espetacular expôs sua própria contradição. Ao perceber a monotonia das apresentações exclusivamente eqüestres, adotou a diversificação da arte dos saltimbancos, já que as novas regras de comercialização da economia (e da cultura) provocaram o esvaziamento das feiras e suas práticas culturais, disponibilizando um contingente razoável de saltadores, acrobatas, prestidigitadores etc. Fechados em um espaço, com a correspondente cobrança de ingressos, a habilidade sobre o cavalo associou-se aos famigerados saltimbancos errantes, dando origem ao circo moderno e seu espetáculo. Ao menos sob a forma de espetáculo, a aristocracia e a plebe se encontraram.

Mas o espetáculo nascido naquela oportunidade e que se mantém até os dias atuais é apenas demonstração de habilidades? Certamente, não. Para esse espetáculo, além das habilidades, concorrem pelo menos outros seis elementos: coreografia, música, indumentária, efeitos de luz, linguagem falada e animais selvagens. Se considerarmos que o espetáculo é antecedido pelas mensagens dos cartazes e da propaganda, então um oitavo elemento deve ser considerado. Todo esse complexo sustenta a 
concepção do circo como uma linguagem multimídia (Bouissac, 1970). Muitos desses elementos, contudo, estão presentes também em outras linguagens artísticas. Nelas, eles chegam a exercer o papel de elementos fundantes, matrizes a partir das quais se erguem formas artísticas específicas.

A literatura tem na língua a sua matriz; a música, nos sons; a pintura, nas cores, traços e formas. Qual seria a matéria principal do espetáculo de circo? Linguagem, sons, cores, traços e formas dele participam, mas não chegam a ser fundantes. A matriz do circo é o corpo, ora sublime, ora grotesco. O corpo não é uma coisa, mas um organismo vivo que desafia seus próprios limites. $\mathrm{O}$ artista tem consciência da possibilidade do fracasso, que pode se dar em qualquer espetáculo, independentemente de todo treino e de toda perícia. A queda do trapezista em seu desempenho não é apenas imagem ficcional. O que o público presencia é a construção do suspense, do calafrio, seguido de sua superação. No momento seguinte, o espetáculo é interrompido e o público é acometido pela descontração da performance dos palhaços. O corpo feito espetáculo deixa de lado a roupa cotidiana que o esconde para se mostrar em sua grandeza contraditória, no jogo incessante entre o sublime e o grotesco. Espetacularmente, ele se desnuda para revelar toda a sua potencialidade. $\mathrm{O}$ fracasso é evidente, para ser superado, no momento seguinte, com o riso dos palhaços. A morte está presente nos mais diversos números de acrobacias. Os ginastas dão ao corpo a dimensão de grandeza que o espírito humano, em sua história, raras vezes reconheceu. O corpo sublime, no chão ou nas alturas, desafia, em forma de espetáculo, as leis naturais. O circo trouxe às artes cênicas, no século XIX, a reposição do corpo humano como fator espetacular.

$\mathrm{O}$ ambiente francês do período era de embate acirrado entre as regras rígidas dos clássicos e os impulsos do romantismo de subversão dessas normas. Em pleno século XIX, após a agitação revolucionária e a despeito das investidas de Napoleão, as regras clássicas continuavam imperando no terreno da criação literária. Essas normas colocavam o teatro no centro da atividade literária e, no interior deste, a Comédie Française. Os gêneros ainda se colocavam como estanques, e o ideal era a convergência entre o tempo ficcional e o tempo real, em uma leitura das mais acirradas da verossimilhança. Os românticos, por seu turno, procuraram subverter a racionalidade dos clássicos e buscaram libertar a inspiração das correntes da lógica e da técnica das criações. Inspirados em Shakespeare, eles propuseram a imaginação, o lirismo e a liberdade criadora como norteadores da criação artística. Com isso, as barreiras entre o trá- 
gico e o cômico seriam deliberadamente abolidas e o emergente drama trabalharia com o jogo de oposições entre o riso e as lágrimas, o corpo e a alma, o homem e a sociedade etc. Estavam mais do que postas as ligações da cena com a história, sob o lema da "cor local". As paixões deixaram de se submeter à rigidez dos versos e se exacerbaram, especialmente quanto ao conflito com as imposições da ordem social e da moral. Valorizando o eu, o romantismo explorou os desacertos deste com as regras sociais. Igualmente, as tímidas alusões dos clássicos acerca do corpo e da sexualidade ganharam a primazia da liberdade: "O herói romântico afirmava corajosamente o seu direito à liberdade afetiva. Depois, só lhe restava, como saída satisfatória para a moral pública, morrer com dignidade" (Prado, 1978, p.177).

Nesse quadro, o espetáculo circense, nascido da junção da arte eqüestre com outras formas de espetáculos das feiras e dos saltimbancos, colocou-se nitidamente no terreno romântico, especialmente porque conseguiu a confluência de dois dos mais caros ideais do romantismo: a exaltação do nacionalismo e a retomada e valorização das formas populares de espetáculos, uma vez que, nessas, segundo a crença romântica, estariam as raízes da identidade de um povo e de uma nação.

O circo, por outro lado, também manifestava sua predileção pelo risco e pelo impossível, dando asas à imaginação, ignorando as barreiras entre o sério e o risível, entre o trágico e o cômico. Ele incorporou valores antagônicos em um mesmo espetáculo e, ao contrário da valorização dos atos intelectualistas do espírito, própria dos clássicos, o circo propôs o corpo como princípio espetacular, vindo assim ao encontro da tão almejada valorização do eu. O espetáculo circense expôs e valorizou as sutilezas da anatomia humana, seja pela via do sublime, seja pela do grotesco.

No ambiente do século XIX, o circo reservou à mulher um lugar de destaque, e a graça feminina, nos exercícios da Alta Escola, associou-se aos movimentos do cavalo. O mito da criatura frágil foi testado diante da força instintiva do animal. Mais do que a graça, o espetáculo circense explorou e conciliou o erotismo com os "fantasmas os mais etéreos da sensibilidade romântica" (Auguet, 1974, p.27).

Pelo espetáculo circense, as sensações do público oscilam entre o arrepio diante do possível fracasso do ginasta e a gargalhada revitalizadora provocada pelos gracejos desmedidos dos palhaços. Assim, o espetáculo se desloca com facilidade e maestria entre a morte e o riso (ibidem, p.7). No espetáculo circense, o fogo não queima; no trapézio, o homem voa; o aramista vence distâncias equilibrando-se sobre um fio; o equilibrista fica suspenso sobre objetos inusitados, que no diaa-dia não se pres- 
tam a esse fim; os animais selvagens são dóceis etc. No caso dos acrobatas, a emoção da queda fatal é posta por inteira, para ser superada, no momento seguinte, com o riso do palhaço. Não se trata, entretanto, de uma morte espetacular. A morte está presente, como possibilidade constante, nos mais diversos números de acrobacias, especialmente os aéreos. O corpo que vivencia tal situação é um corpo sublime que não se diferencia entre a vida e o espetáculo e que, nas alturas, desafia as leis da física. Diante dessas performances, o público, no limite extremo, experimenta o espanto, o terror e o despontar da morte em sua real possibilidade.

No campo da investigação filosófica, Edmundo Burke é, nos tempos modernos, considerado o precursor da reflexão sobre o sublime, a partir de sua obra Uma investigação filosófica sobre a origem de nossas idéias do sublime e do belo, cuja primeira edição é de 1757. O autor aplica o conceito de sublime explicitamente às coisas naturais. Se estendermos o seu conceito aos feitos circenses, então suas palavras prestam-se fielmente à compreensão do espanto e da sublimidade do espectador circense. Segundo ele:

A paixão a que o grandioso e sublime na natureza dão origem, quando essas causas atuam de maneira mais intensa, é o assombro, que consiste no estado de alma no qual todos os seus movimentos são sustados por um certo grau de horror. Nesse caso, o espírito sente-se tão pleno de seu objeto que não pode admitir nenhum outro nem, conseqüentemente, raciocinar sobre aquele objeto que é alvo de sua atenção. Essa é a origem do poder do sublime, que, longe de resultar de nossos raciocínios, antecede-os e nos arrebata com uma força irresistível. O assombro, como disse, é o efeito do sublime em seu mais alto grau; os efeitos secundários são a admiração, a reverência e o respeito. (Burke, 1993, p.65)

Por que essa sensação? Porque no espetáculo circense o desempenho artístico não se dá por metáforas ou símbolos. Os artistas, especialmente aqueles que se entregam aos números de risco, não estão ali representando papéis, tal como ocorre nos palcos, nos espetáculos teatrais. Se houver alguma espécie de semiose nos números que envolvem acrobacias arriscadas, ela é dada pelo próprio desempenho do artista. O sentido, portanto, é oriundo do corpo e é encontrado na performance em si mesma, no exclusivo tempo e momento de sua duração. Ele não extrapola esse limite. O desempenho, nesse caso, não remete a nenhuma realidade exterior e ausente. Em outras palavras, não há nenhuma espécie de figurativismo, para adotar uma terminologia própria das artes plásticas. $\mathrm{O}$ artista não representa: ele vive seu próprio tempo, com seu ritmo e pul- 
sação próprios. Ou melhor, ele "representa" porque está inserido em um espetáculo, mas é uma representação de si mesmo ao demonstrar e vivenciar, em público, as suas habilidades. Representação e vida fundem-se em um mesmo ato. No circo, os corpos dos atletas e acrobatas não simbolizam, não são figurativos, não são presença na ausência. Eles são aquilo que fazem (Handelman, 1991, p.212 ss.). Como espetáculo, representam aquilo que são.

O olhar do público sobre os acrobatas, em um primeiro momento, é marcado por uma relação harmoniosa. Trata-se de uma relação entre iguais, ainda que dispostos em espaços distintos, motivada por uma percepção normal, sem dissonância entre o espectador e o artista. Há uma correspondência entre o interior (do público) e o exterior (o espetáculo). Tão logo têm início as demonstrações de risco, contudo, essa relação habitual se rompe. Um certo estranhamento toma conta do público e abre-se o caminho para a surpresa ou o assombro, marcado pela ausência da capacidade de raciocínio. Rompe-se, assim, a percepção primeira, revelando os desníveis entre quem vê e aquilo que vê. O número arriscado provoca surpresa e ao mesmo tempo denuncia a incapacidade do público em alcançar a proporção dada ao corpo pelo acrobata. O espanto toma conta e aniquila a possibilidade de entendimento da exibição. Sujeito apreciador e objeto apreciado estão em estado de ruptura assombrosa. No momento seguinte, entretanto, essa ruptura é superada com a eficiência da exibição e nesse momento a platéia retoma o equilíbrio entre as instâncias desiguais, manifestando a admiração e o regozijo perante a exibição de risco. Com isso, os estágios anteriores da percepção habitual e do estranhamento são superados, mantendo-se viva, contudo, o valor simbólico do assombro vivenciado, que é dado pela estrita exposição corporal. O corpo constrói e revela sentidos até então desconhecidos. ${ }^{3} \mathrm{O}$ momento sublime é superado, porém mantém-se vivo na memória.

À experiência do sublime o espetáculo circense acresce a exposição do grotesco. Esta, de fato, não anula a anterior. Ao contrário, serve também de antídoto para sedimentar a experiência do assombro. O relaxamento provocado pelo riso não apenas é contraponto à tensão que o sublime explora, como também direciona o espectador ao exercício do raciocínio. Mas também aqui o corpo tem a primazia. No sentido inverso

\footnotetext{
3 "Pois é precisamente o caráter semiótico do momento sublime que preserva a sublimação necessária ao sublime" (Weiskel, 1994, p,43). Weiskel analisa as três fases do momento sublime no ato de transcendência, recorrendo à experiência poética. Em nossa reflexão, transferimos essa análise para o processo de construção e recepção do espanto no espetáculo circense, nos números acrobáticos de risco.
} 
do sublime, os palhaços exploram o lado obscuro do corpo, aquela dimensão que o dia-a-dia almeja esconder.

Basta uma alusão ao corpo e, então, tem se a passagem do trágico ao cômico, do emotivo ao risível. Essa é uma das observações de Henri Bergson sobre o cômico. Chamar a atenção para o corpo do herói é deslocar a cena para o terreno da comicidade. Os heróis trágicos não bebem, não comem, não se vestem: "Inclusive, na medida do possível, nunca se sentam. Sentar-se no meio de uma fala seria lembrar que se tem corpo" (Bergson, 1980, p.33).

Bergson tem uma visão negativa do riso e do cômico. O maior intento da arte, em sua opinião, seria a consolidação da moral. Princípios éticos antecedem os estéticos e se realizam na arte séria, distante, portanto do relaxamento do riso. O riso, por sua vez, tem as seguintes condições para se efetivar: ele é essencialmente humano, é insensível, é um fenômeno coletivo.

A comicidade só é possível para o homem. Pode-se rir de uma coisa ou de um animal desde que neles se projetem valores e hábitos dos homens. Quando risível, o objeto ou o animal passam por um processo de "subjetivação", momento em que características humanas a eles se agregam.

O cômico é insensível e requer unicamente o jogo da razão. Ele passa ao largo da emoção. De acordo com Bergson (1980, p.13), “o cômico exige algo como certa anestesia momentânea do coração para produzir todo o seu efeito. Ele se destina à inteligência pura". A vida é identificada com a liberdade e comporta um tom grave, denso em sua dramaticidade que apenas a arte séria pode dela se aproximar. A transformação dessa seriedade em algo risível resulta em assumir a vida como ilusão e aparência, por absoluto jogo do raciocínio e não por intermédio do que o autor admite como arte.

Por sua vez, a inteligência que sustenta o cômico necessita da revelação e do reconhecimento de outras inteligências. O riso, então, não se dá de forma isolada: ele é sempre um riso coletivo. Ele é, portanto, um riso social e responde a certas necessidades. Ao suprir essas necessidades, ele assume especialmente uma finalidade corretiva. Ao ressaltar o ridículo e o absurdo, o cômico aponta o desvio dos valores, com vistas à retomada da ordem e do positivo (Ferroni, 1974, p.27). Nesses termos, o cômico aponta os desvios e cabe ao riso o ato corretivo de revisão e de retorno à ordem. Para tanto, ele apela às inteligências, ao mesmo tempo que se ergue como uma espécie de proteção extensiva à coletividade que o exercita. 
Sabe-se que a idéia de duração ocupa um lugar central nas reflexões de Bergson. De acordo e a partir dela, tudo é novo e concomitantemente conservado. Memória e conservação são as bases do élan vital, fonte da vida, uma espécie de consciência criadora que encontra em si as reações necessárias que a cada momento a vida exige. Nada se repete, e a vida é incessante fluir porque opera com as noções de tensão e elasticidade. A vida não é mecânica: ela é qualidade conservada e sempre nova (Giacomoni, 1995, p.184 ss.).

Diante desse quadro, o cômico é oposto à vida e representa a perda da tensão e da elasticidade. Ele se reduz a esquema, repetitividade, rigidez, enfim, ele é máscara e automatismo. O gesto repetitivo, quando percebido, é objeto de riso e, nesse caso, denuncia o "mecanismo instalado na vida e imitando a vida. É a comicidade" (Bergson, 1980, p.24-5).

A idéia do mecânico calcado no vivo prevê um processo de coisificação do homem objeto do riso. O homem coisificado opera por automação e dele se ausentam os princípios da tensão e da elasticidade. A flexibilidade, assim, cede lugar à matéria rígida e esquemática. Essa operação, portanto, resulta do adormecer da consciência de si, momento em que a alma estática se materializa em um corpo rígido e esquemático.

Bergson arrola exemplos de comicidade dos palhaços circenses para demonstrar essa "coisificação". As "facécias da arte do palhaço" são as cambalhotas e os movimentos. Toda a atenção do público dirigese, então, para o corpo, para os saltos, para um encontro/desencontro de corpos que não são corpos, mas coisas: não são homens de carne e osso, mas bolas de borracha. Em um outro exemplo, duas personagens calvas e de cabeças enormes batem um na cabeça do outro, até parecerem bastões rígidos (ibidem, 1980, p.36-7).

Essa comicidade está presa apenas ao mecanismo do corpo? Há uma nítida distinção entre a percepção do mecânico e do cômico no cotidiano e a percepção do cômico a partir da representação do mecânico. No dia-a-dia, para se efetivar, a percepção do mecânico requer a inconsciência daquele que se automatizou e que se tornou objeto de riso. Para representar o corpo mecanicamente, em compensação, há necessidade de um perfeito domínio dele, que resulta de um longo aprendizado, momento de exercício pleno da intuição, de forma a se conseguir um estado interior correspondente àquela representação. Em outras palavras, esse corpo que representa o mecanismo está integralmente movido por um estado de concentração, estado esse que é e deve ser controlado por seu espírito. O palhaço domina uma série de situações: o roteiro dramatúrgico propriamente dito; o estado de atenção e descontração do público; o conheci- 
mento de suas possibilidades corporais para a execução dos movimentos; uma atenção redobrada para os motivos e momentos que possibilitam o exercício da improvisação etc. Ou, em linguagem bergsoniana, esse ator deve estar em estado de alerta, momento em que se acionam os requisitos da tensão e da elasticidade, não apenas no corpo, mas também no espírito do ator. Ele está ali por inteiro.

O palhaço não é uma máscara fixa, embora carregue traços tipológicos que o identificam. A máscara/maquiagem do palhaço é individual e traz as peculiaridades psicossociais que o artista imprime à personagem. O palhaço é, a um só tempo, ator e autor de sua personagem e das cenas que representa. A graça e o riso não se encontram, no circo, na dramaturgia preestabelecida. O texto dramático, nem sempre solidificado na escrita, é apenas um roteiro sucinto, com motivos gerais que se prestam à improvisação e à criatividade do artista. $\mathrm{O}$ recurso preferencial do palhaço é seu próprio corpo. Gestos, modo de falar, repertório, roupas, máscara e maquiagem são a aparência de uma singular personalidade. $\mathrm{O}$ palhaço é, a um só tempo, ator e autor de sua personagem e das cenas que representa. A base de sua interpretação não é dada pela ficção literária, movida por intuitos nobres. Ela se exerce em um outro registro, exatamente o do corpo, subjugado historicamente pela grandeza da alma. $\mathrm{Na}$ arte do palhaço, não está presente a manifestação de ideais, de um espírito elevado e nobre. Nela, termina prevalecendo a ação física, quando o corpo sobe à cena para dizer, contraditoriamente, que ele está sendo costumeiramente esquecido. Nesse caso, o sublime não se presta a esclarecê-lo e em seu lugar desponta o grotesco.

O corpo cômico, relegado ao mecanismo na concepção do filósofo francês, segundo o ensaísta russo, Mikhail Bakhtin, encontra sua valorização no realismo grotesco das formas cômicas populares.

O palhaço é um personagem-tipo que opera com a síntese de dois universos distintos: de um lado, nota-se nele uma herança cômica popular e, nesse caso, ele pode ser tomado como uma espécie de continuador das máscaras da commedia dell'arte; de outro, ele manifesta uma espécie de subjetivação, na medida em que os traços psicológicos e físicos, próprios do ator, são estendidos à personagem e por ela explorados (Pantano, 2001, p.64-103).

A construção da personagem, assim, obedece a um determinado perfil individual, que se apóia nas características corporais do ator e em sua própria subjetividade. Mas, para alcançar o estatuto da personagem, o ator procura adequar suas matrizes internas às características tipológica do palhaço, oriundas da tradição da bufonaria. A síntese desses universos 
distintos propicia a expressão de uma subjetividade por meio de um tipo cômico aparentemente imutável. Isso confere ao palhaço um grau de universalidade que se manifesta de forma única. Ou seja, ele é, concomitantemente, único e universal. Assim, ele materializa no corpo, na indumentária, nos gestos, na maquiagem e na voz os perfis subjetivos e psicológicos que fundamentam sua personagem. Obviamente, não se trata daquela psicologia profunda que caracteriza o teatro dramático de cunho psicológico.

O palhaço, então, tem uma configuração especial: opera a partir de tipos genéricos, mas confere ao tipo eleito uma caracterização individual. Talvez seja essa uma das razões que levaram Bakhtin (1993, p.25) a reconhecer no palhaço e no circo uma sobrevivência desnaturalizada e atenuada da concepção do corpo do realismo grotesco. As características individuais ajustam-se a um tipo determinado e se materializam no corpo do ator, acompanhados da indumentária e da maquiagem. Esse corpo, ao contrário do acrobata, não é perfeito e acabado, o que induziria à sublimidade. O corpo do palhaço é disforme, permeado de trejeitos, e busca a ênfase no ridículo, pela exploração dos limites, deficiências e aberrações. Freqüentemente, os palhaços recorrem à sexualidade, motivo maior para realçar os desejos que se mantêm adormecidos no dia-a-dia. É um corpo livre das regras da moral, em que predomina a licenciosidade. Não se trata, contudo, daquele corpo automatizado ao qual Bergson se referiu. É um corpo que tem o domínio espiritual do ator, em estado pleno de alerta, porque sua interpretação não está prevista anteriormente em um texto dramatúrgico e muito menos na quietude da platéia. $\mathrm{O}$ público intervém no espetáculo e na performance dos palhaços. A improvisação é a insólita ferramenta do palhaço e, nesta, o acaso e o inesperado exercem uma influência decisiva.

No oposto do improviso do palhaço, o circo apresenta o mais alto rigor de treinamento e preparação. Na execução do sublimado salto triplo mortal, o artista jamais pode se entregar ao acaso. O treinamento milimetricamente projetado e executado pelo acrobata e o improviso dos clowns trazem, de um lado, o esvaziamento da idéia de interpretação do ginasta e, de outro, a representação elevada ao seu mais alto grau de comunicabilidades, porque interage constantemente com a platéia. Nos dois pólos, contudo, o corpo humano coloca-se como fundamento, oscilando entre $o$ sublime e o grotesco.

Para finalizar, retomaria o argumento de Herbert Marcuse, exposto no ensaio "Sobre o caráter afirmativo da cultura", quando o autor aborda a conversão do corpo em mercadoria, para fins de fruição: 
Onde o corpo se tornou inteiramente objeto, coisa bela, ele possibilita imaginar uma nova felicidade. Na subordinação extrema à reificação, o homem triunfa sobre a reificação. A qualidade artística do corpo belo, ainda hoje presente unicamente no circo, nos cabarés e nos shows, essa leveza e frivolidade lúdicas, anuncia a alegria da libertação do ideal que o homem pode atingir quando a humanidade, convertida verdadeiramente em sujeito, dominar a matéria. Quando se supera o vínculo com o ideal afirmativo, quando existe fruição sem qualquer racionalização e sem o mais leve sentimento de culpa punitivo no plano de uma existência provida de sabedoria, quando os sentidos se libertam inteiramente da alma, então surge a primeira luz de uma outra cultura. (1997, p.115)

BOLOGNESI, M. F. The body as principle. Trans/Form/Ação (São Paulo), v.24, p.101-112, 2001.

- ABSTRACT: The raw material of the circus show is the artist's body, as something at times sublime, at times grotesque. The sublime body, on the floor or in the heights, challenges, as a sort of spectacle, the laws of nature. Afterwards, the show is "interrupted" and the public is invaded by the relaxation and the grotesquerie of the clowns. The circus show thus moves, with ease and mastery, between laughter and death.

- KEYWORDS: Circus; clown; laughter.

\section{Referências bibliográficas}

AUGUET, R. Histoire et légende du cirque. Paris: Flammarion, 1974.

. Les fêtes populaires et le comique clownesque. In: FABBRI, J., SALLÉE, A. (Org.) Clowns \& farceurs. Paris: Bordas, 1982.

BAKHTIN, M. A cultura popular na Idade Média e no Renascimento: o contexto de François Rabelais. São Paulo: Hucitec, 1993.

BERGSON, H. O riso: ensaio sobre a significação do cômico. Rio de Janeiro: Zahar, 1980.

BOUISSAC, P. The circus as a multimedia language. Language Sciences, v.11, p.1-7, 1970.

BURKE, E. Uma investigação filosófica sobre a origem de nossas idéias do sublime e do belo. Campinas: Papirus, 1993.

CUPPONE, R. CDA. Il mito della Commedia dell'Arte nell'ottocento francese. Roma: Bulzoni, 1999. 
DUARTE, R. H. Noites circenses: espetáculos de circo e teatro em Minas Gerais no século XIX. Campinas: Editora da Unicamp, 1995.

FERRONI, G. Il comico nelle teorie contemporanee. Roma: Bulzoni, 1974.

FO, D. Qu'est-ce qu'un clown? In: FABBRI, J., SALLÉE, A. (Org.) Clowns et farceurs. Paris: Bordas, 1982. p.83-8.

GIACOMONI, P. Il comico secondo Bergson. In: BANFI, E. (Org.) Sei lezioni sul linguaggio comico. Trento: Dipartimento di Scienze Filologiche e Storiche, 1995. p.169-96.

HANDELMAN, D. Symbolic types, the body, and circus. Semiotica, v.85, n.3/4, p.205-25, 1991.

JANDO, D. Naissance du clown. In: FABBRI, J., SALLÉE, A. (Org.) Clowns \& farceurs. Paris: Bordas, 1982. p.60-73.

KELLY, E., KELLEY, F. B. Clown. New York: Buccaneer Books, 1996.

LITTLE, W. K. The rhetoric of romance and the simulation of tradition in circus performance. Semiotica, v.85, n.3/4, p.227-55, 1991.

MACEDO, J. R. Riso, cultura e sociedade na Idade Média. Porto Alegre: Editora da Universidade/IFRGS, 2000.

MARCUSE, H. Cultura e sociedade. Rio de Janeiro: Paz e Terra, 1997. v.1.

PANTANO, A. A. A personagem palhaço: a construção do sujeito. Marília, 2001. Dissertação (Mestrado) - Faculdade de Filosofia e Ciências, Universidade Estadual Paulista.

PRADO, D. de A. O teatro romântico: a explosão de 1830. In: GUINSBURG, J. (Org.) O romantismo. São Paulo: Perspectiva, 1978. p.167-84.

PRETINI, G. (Org.) Antonio Franconi e la nascita del circo. Reana del Rojale: Trapezio Libri, 1988.

. Thesaurus circensis. Reana del Rojale: Trapezio Libri, 1990. 2v.

PROPP, V.Comicidade e riso. São Paulo: Ática, 1992.

RÉMY, Tristan. Entrées clownesques. Paris: L'Arche, 1962.

. Petit histoire du cirque: acrobaties spectaculaires et spectacles de curiosités. In: PRETINI, G. (Org.) Thesaurus circensis. Reana del Rojale: Trapezio Libri, 1990. pt.2, p.927-54. (Texto original de 1961).

SALLÉ, A. Des siècles de farceurs. In: FABBRI, J., SALLÉE, A. (Ed.) Clowns et farceurs. Paris: Bordas, 1982. p.74-82.

SANTARCANGELI, P. Homo ridens: estética, filologia, psicologia, storia del comico. Firenze: Olschk, 1989.

SPEAIGHT, G. The book of clowns. London: Sidgwick \& Jackson, 1980.

WEISKEL, T. O sublime romântico: estudos sobre a estrutura e psicologia da transcendência. Rio de Janeiro: Imago, 1994. 